\title{
QUALIDADE DE LUZ NO CULTIVO IN VITRO DE Dendranthema grandiflorum cv. Rage: CARACTERÍSTICAS MORFOFISIOLÓGICAS
}

\author{
Quality of light on the in vitro culture of Dendranthema grandiflorum cv. Rage: \\ morphophysiological characteristics
}

\author{
Francyane Tavares Braga', Moacir Pasqual' ${ }^{2}$ Evaristo Mauro de Castro ${ }^{3}$, \\ Samantha Léa Dignart ${ }^{4}$, Gabriel Biagiotti ${ }^{5}$, Jorge Marcelo Padovani Porto ${ }^{6}$
}

\begin{abstract}
RESUMO
Na micropropagação a manutenção das salas de crescimento torna a técnica onerosa, aumentando assim, a necessidade de conduzir estudos envolvendo a manipulação e o controle das condições de cultivo para otimizar o crescimento in vitro. A qualidade de luz pode alterar a morfogênese das plantas por meio de uma série de processos mediados por receptores, que absorvem a luz na região do vermelho e azul do espectro, sendo, portanto, uma maneira viável de aumentar a qualidade das mudas micropropagadas. Objetivou-se com o presente trabalho avaliar o efeito da qualidade de luz, na morfofisiologia de crisântemo [Dendranthema grandiflorum (Ramat.) Kitam] micropropagadas. Os explantes constituíram-se de segmentos nodais cultivados in vitro contendo uma gema. Foi utilizado o meio MS acrescido de $15 \mathrm{~g} . \mathrm{L}^{-1}$ de sacarose e as condições de incubação foram: (SC) sala de crescimento, sendo este o tratamento controle; (CV) casa-de-vegetação luz natural e casa-de-vegetação com sombrite $50 \%$ nas cores: preto, vermelho e azul. A avaliação foi efetuada 60 dias após a implantação do ensaio. Para número de folhas, SC mostrou-se a forma mais efetiva de incubação, com maior número médio de folhas. O mesmo ocorreu com número de raízes, brotações e comprimento médio de raízes. Para comprimento de parte aérea, SC e CV com proteção de sombrite: azul, preto e vermelho foram mais eficientes. Quanto aos aspectos anatômicos, para densidade estomática o maior número de estômatos $/ \mathrm{mm}^{2}$ foi observado em CV sem sombrite e CV com sombrite vermelho. Para diâmetros polar e equatorial dos estômatos, CV sem sombrite, seguidos de CV azul, vermelho, apresentaram maiores diâmetros. Com os resultados apresentados, é possível recomendar a utilização de luz natural no cultivo in vitro de crisântemo, porém não é recomendado a manipulação da qualidade espectral.
\end{abstract}

Termos para indexação: Micropropagação, luz natural, qualidade espectral e crisântemo, Dendranthema grandiflorum.

\section{ABSTRACT}

In micropropagation, the maintenance of the growth rooms is labor-consuming and expensive, which increases the necessity of studies involving the manipulation and control of the culture conditions to optimize the in vitro growth. The quality of light may modify the morphogenesis of the plants through many processes mediated by receivers, which absorb the light in the blue and red region of the spectrum, being therefore, a viable way to increase the quality of the micropopagated plants. This work aimed at evaluating the effect of the spectral alteration under conditions of natural light on the morphophysiology of micropropagated chrysanthemum [Dendranthema grandiflorum (Ramat.) Kitam] plants. Nodal segments with one bud cultivated in vitro were used as explants. The medium used was MS with half of its salts concentration supplemented with $15 \mathrm{~g} . \mathrm{L}^{-1}$ sucrose. The incubation conditions were growth room (GR), this being the control treatment, greenhouse (GH) without shadow protection and greenhouse with 50\% shadow in the colors black, blue, and red. The evaluation was done 60 days after the implantation of the assay. For the leaf number, GR showed to be the most effective incubation form, with a higher number of leafs. The same occurred with the number of roots and shoots and the average length of roots. For the aerial part length, GR and GH with shadow protection in all three colors were more efficient. Considering the anatomical aspects for stomatal density, a greater number of stomatal $/ \mathrm{mm}^{2}$ was observed in $\mathrm{GH}$ without shadow protection and in GH with red shadow protection. For the polar and equatorial diameters of the stomata, GR without shadow protection, followed by GR with shadow protection in the colors blue and red, presented a bigger stomatal diameter. With the presented results, it is possible to recommend the use of natural light for the in vitro cultivation of chrysanthemum, however, the manipulation of the spectral quality is not recommended.

Index terms: Micropropagation, natural ligth, spectral quality and chrysanthemum, Dendranthema grandiflorum.

(Recebido em 22 de setembro de 2006 e aprovado em 9 de abril de 2008)

\footnotetext{
'Bióloga, Doutoranda - Departamento de Agricultura/DAG - Universidade Federal de Lavras/UFLA - Cx. P. 3037 - $37200-000$ - Lavras, MG ftbraga@yahoo.com.br

${ }^{2}$ Engenheiro Agrônomo, Professor - Departamento de Agricultura/DAG - Universidade Federal de Lavras/UFLA - Cx. P. 3037 - $37200-000$ - Lavras, MG mpasqual@ufla.br

${ }^{3}$ Engenheiro Florestal, Professor - Departamento de Biologia/DBI - Universidade Federal de Lavras/UFLA - Cx. P. 3037 - $37200-000$ - Lavras, MG emcastro@ufla.br

${ }^{4}$ Bióloga, Mestre em Fisiologia Vegetal - Rua Generoso Ciríaco Maciel, no 13 Quadra 15 - Jardim Petrópolis - 78070-050 - Cuiabá, MT leadignart@yahoo.com.br

${ }^{5}$ Graduando em Engenharia Florestal - Departamento de Ciências Florestais/DCF - Universidade Federal de Lavras/UFLA - Cx. P. 3037 - $37200-000$ Lavras, MG - biagiotti@yahoo.com.br

${ }^{6}$ Biólogo, Doutorando em Fisiologia Vegetal - Departamento de Biologia/DBI - Universidade Federal de Lavras/UFLA - Cx. P. 3037 - $37200-000$ - Lavras, MG -marcelo_pado@yahoo.com.br
}

Ciênc. agrotec., Lavras, v. 33, n. 2, p. 502-508, mar./abr., 2009 


\section{INTRODUÇÃO}

As plantas utilizam sinalizadores para promover determinados padrões de crescimento e estes respondem à qualidade de luz, crescendo sob uma região limitada no espectro visível e exibindo morfologia e fisiologia determinadas pelas variações ocorridas neste espectro (ALMEIDA \& MUNDSTOCK, 2001; ESKINS \& BEREMAND, 1990). A dependência das plantas à luz é um processo complexo que envolve a ação combinada de fotorreceptores que controlam estádios variados no desenvolvimento.

Salas de crescimento, geralmente, são equipadas com lâmpadas fluorescentes que emitem luz branca de similaridade espectral entre as bandas. A irradiância fornecida primariamente na sala de crescimento afeta o desenvolvimento das plantas, principalmente por meio de alterações fotomorfogênicas, alterações estas observadas, principalmente, na formação dos tecidos do mesofilo e na ineficiência do mecanismo de abertura e fechamento dos estômatos, afetando sua funcionalidade (REZENDE, et al. 2008). As salas de crescimento também representam um dos maiores custo na produção de mudas micropropagadas, tornando a técnica bastante onerosa.

Estudos da qualidade de luz na micropropagação ainda são escassos e também não são claros os efeitos do espectro e de níveis de irradiância no crescimento de plântulas durante o cultivo in vitro. Alguns estudos revelam que, com a variação na qualidade da luz, pode-se manipular o crescimento in vitro de diversas espécies, de maneira alternativa à adição de reguladores de crescimento ao meio de cultura. A qualidade espectral afeta também estruturalmente a anatomia das folhas, parecendo exercer maiores efeitos durante a expansão foliar, exibindo alto grau de plasticidade tanto anatômico como fisiológico (SAEBO et al., 1995; SCHUERGER et al., 1997; SIMS \& PEARCY, 1992; DOUSSEAU, et al. 2008), como germinação, inibição de alongamento do hipocótilo, expansão dos cotilédones e das folhas, enverdecimento e biossíntese de pigmentos, alongamento do caule e indução ao florescimento em plantas propagadas convencionalmente (SAITOU et al., 2004; TAIZ \& ZEIGER, 2004; TSEGAY et al., 2005). Neste contexto, poucos são os estudos do uso de alteração na qualidade espectral utilizando luz natural na propagação in vitro.

A complexidade e a variabilidade da radiação natural, e as reações de múltiplas respostas das plantas ao ambiente de cultivo, tornam difícil dizer como determinada manipulação na radiação natural afetará uma resposta da planta.

Diante do exposto, objetivou-se, com o presente trabalho, estudar a qualidade da luz na propagação in vitro de Dendranthema grandliflorum (Ramat.) Kitam cv. Rage, nas características fitotécnicas, anatômicas e fisiológicas.

\section{MATERIAL E MÉTODOS}

O material vegetal consistiu-se de segmentos nodais de crisântemo (Dendranthema grandiflorum) cv. RAGE. Os segmentos foram inoculados em meio MS (MURASHIGE \& SKOOG, 1962) acrescido de 15 g.L-1 de sacarose, $6 \mathrm{~g} . \mathrm{L}^{-1}$ de agar e teve seu $\mathrm{pH}$ ajustado para 5,8 antes da autoclavagem a $121^{\circ} \mathrm{C} 1,2$ atm, durante 20 minutos. Quinze m.L $\mathrm{L}^{-1}$ do meio foi vertido em tubos de ensaio.

O experimento foi conduzido em casa-de-vegetação, sendo os tubos, após a inoculação, fechados com tampas de polipropileno e vedados com plástico do tipo parafilme. $\mathrm{O}$ material foi colocado diretamente sobre as bancadas (casa-de-vegetação sem proteção de sombrite-CV) ou sob malhas especiais que, segundo o fabricante, alteram o espectro de luz solar ou, ainda, sob proteção adicional de sombrite $50 \%$ preto (CVSP). As malhas coloridas utilizadas foram fornecidas pela empresa Polysac Plastic Industries®. Utilizou-se a malha ChromatiNet Vermelha 50\% (CVSV), produzida com a finalidade de alterar espectro da luz, reduzindo as ondas azuis, verdes e amarelas e acrescentando as ondas na faixa espectral do vermelho e vermelho-distante. Outro tratamento foi feito com a malha ChromatiNet Azul $50 \%$ (CVSA) que, segundo o fabricante, muda o espectro da luz, reduzindo as ondas na faixa do vermelho e vermelho distante e acrescentando as ondas azuis.

Os tubo também foram incubados em sala de crescimento (SC), com fotoperíodo de 16 horas, temperatura de $25 \pm 2^{\circ} \mathrm{C}$, com radiação de $52 \mathrm{~W} \cdot \mathrm{m}^{-2} \mathrm{~s}^{-1}$ (LI-200SA; Li-cor, Lincoln, Nevasca, USA), fornecida por lâmpadas brancas fluorescentes, para servirem como tratamento controle.

A intensidade da radiação foi mensurada diariamente por meio de três sensores de radiação acoplados a um sistema de registro (LI 1400; Licor. Neb).

Após 60 dias de cultivo, o experimento foi avaliado através de:

- Características Fitotécnicas: número de brotações, número de folhas e raízes por planta, comprimento da parte aérea e comprimento médio das raízes.

- Características Anatômicas: As plantas foram fixadas em álcool etílico 70\% GL. O número de estômatos foi determinado de acordo com a metodologia de Laboriau et al. (1961). Foram utilizados quatro campos de cinco propágulos por tratamento, para a determinação da densidade estomática. As determinações dos diâmetros polar e equatorial dos estômatos foram realizadas, utilizando-se uma ocular micrométrica acoplada em microscópio óptico, com objetiva com aumento de 40x. 
Delineamento Experimental e Análise Estatística: O experimento foi montado em delineamento inteiramente casualizado, com vinte repetições. Cada repetição foi composta por um tubo contendo um segmento nodal. As médias foram comparadas pelo Teste de Scott-Knott a 5\% de probabilidade.

\section{RESULTADOS E DISCUSSÃO}

Caracterização do ambiente: Os valores médios de radiação recebidos no ambiente de casa-de-vegetação estão apresentados na tabela 1 .

Tabela 1 - Radiações observadas nos microambientes em casa-de-vegetação. CVSS: casa-de-vegetação sem sombrite; CVSV: casa-de-vegetação com sombrite vermelho; CVSA: casa-de-vegetação com sombrite azul; CVSP: casa-de-vegetação com sombrite preto e sala de crescimento SC.

\begin{tabular}{|c|c|}
\hline Ambiente & Radiação $\left(\mathrm{MJ} \cdot \mathrm{m}^{-2} \cdot \operatorname{dia}^{-1}\right)$ \\
\hline CVSS & 2,56 \\
\hline CVSV & 2,53 \\
\hline CVSA & 2,45 \\
\hline CVSP & 1,98 \\
\hline $\mathrm{SC}$ & 52 \\
\hline
\end{tabular}

Características fitotécnicas: Sala de crescimento foi superior para número de folhas, raízes e comprimento de raízes, para número de brotos os tratamentos não apresentaram diferenças significativas (Tabela 2). Trabalhando com Cattleya walkeriana Gardner, cultivadas in vitro em diferentes ambientes (qualidade de luz), Dignart (2006) verificou resultados semelhantes para número de folhas, tendo as plântulas cultivadas em sala de crescimento proporcionado maiores valores comparados com as de casa-de-vegetação. O mesmo autor também observou que a utilização de malhas coloridas em casa-devegetação não resultou em diferenças significativas.

Araújo (2007) também obteve maior número de folhas em plântulas de Cattleya loddigesii Lindl. cultivadas em sala de crescimento.

Para comprimento de parte aérea, o tratamento casade-vegetação, apresentou resultados inferiores aos observados nos demais tratamentos. Resultados semelhantes foram obtidos por Radmann et al. (2001), quando, ao cultivarem Gypsophila paniculata L., sob diferentes intensidades luminosas, observaram que todas as plântulas mantidas em casa-de-vegetação desenvolveram menor comprimento de parte aérea, comparadas a plântulas mantidas em sala de crescimento. $\mathrm{O}$ mesmo foi observado
Tabela 2 - Valores médios para número de folhas (NF), comprimento de parte aérea (CPA), número de raízes (NR), comprimento da maior raiz (CR) e número de brotações (NB) de plântulas de crisâtemo cv. Rage, cultivadas em diferentes ambientes com coberturas coloridas ( $\mathrm{CV}=$ casade-vegetação).

\begin{tabular}{lccccc}
\hline \multicolumn{1}{c}{ Luz } & NF & $\begin{array}{c}\text { CPA } \\
(\mathrm{cm})\end{array}$ & NR & $\begin{array}{c}\text { CR } \\
(\mathrm{cm})\end{array}$ & NB \\
\hline $\begin{array}{l}\text { Casa de } \\
\text { vegetação }\end{array}$ & $22,8 \mathrm{~b}$ & $3,5 \mathrm{~b}$ & $4,4 \mathrm{~b}$ & $5,3 \mathrm{~b}$ & $1,2 \mathrm{a}$ \\
$\begin{array}{l}\text { CV azul } \\
\text { CV preto }\end{array}$ & $24,5 \mathrm{~b}$ & $5,4 \mathrm{a}$ & $4,5 \mathrm{~b}$ & $5,5 \mathrm{~b}$ & $1,4 \mathrm{a}$ \\
$\begin{array}{l}\text { CV vermelho } \\
\begin{array}{l}\text { Sala de } \\
\text { crescimento }\end{array}\end{array}$ & $25,9 \mathrm{~b}$ & $5,5 \mathrm{a}$ & $4,9 \mathrm{~b}$ & $5,9 \mathrm{~b}$ & $1,5 \mathrm{a}$ \\
\hline
\end{tabular}

*Médias seguidas pela mesma letra não diferem entre si pelo teste de Skott-Knott, $\mathrm{p}<0,05$.

por Dignart (2006) que obteve resultados semelhantes, sendo o ambiente sala de crescimento mais eficiente no crescimento de parte aérea em plântulas de orquídeas cultivadas in vitro. Estes resultados podem ser explicados pela baixa luminosidade da sala de crescimento em relação a luz natural, caracterizando um crescimento estiolado dessas plântulas.

Poucos trabalhos têm sido realizados com o objetivo de verificar os efeitos da qualidade de luz ou, mesmo, de diferentes níveis de irradiância no crescimento e no desenvolvimento de espécies cultivadas in vitro. A maioria das pesquisas é realizada com o objetivo de obter protocolos para meios nutritivos, principalmente com o foco direcionado a alterações nas concentrações desses meios, bem como as concentrações dos reguladores de crescimento adicionados ao meio (MARKS \& SIMPSON, 1999).

De modo geral, como já observado em alguns estudos com qualidade espectral, a radiação vermelha promove alongamento da parte aérea (APPELGREN, 1991; MARKS \& SIMPSON, 1999; SILVA \& DEBERG, 1997). Porém, essa característica não é geral e muitos autores citam que a influência da qualidade espectral sobre o crescimento e o desenvolvimento de plantas está associada à espécie vegetal (ANTONOPOLOU et al., 2004; HUNTER \& BURRIT, 2001; SCHUERGER et al., 1997).

No presente estudo, verificou-se que o comprimento de parte aérea foi influenciado tanto pela intensidade luminosa deficiente na sala de crescimento quanto pela qualidade espectral e intensidade luminosa na casa-de-vegetação nos ambientes com as malhas, uma vez que não houve diferença significativa entre os ambientes. Lee (2000), ao trabalhar com duas espécies de 
Hopea, observou que a intensidade de luz foi mais significativa no desenvolvimento do que a variação da qualidade espectral.

Na tabela 2, observa-se que o maior número $(10,7)$ e comprimento das raízes $(9,8 \mathrm{~cm})$ ocorreu em ambiente de cultivo sala de crescimento quando comparado ao de casade-vegetação. Dignart (2006), em seu trabalho com Cattleya, não observou diferença entre os tratamentos com qualidade espectral para comprimento de raízes, porém, quanto ao número de raízes, foi verificado que em sala de crescimento com sombrite azul, proporcionou média inferior à dos demais tratamentos. $\mathrm{O}$ mesmo foi observado em trabalho realizado com Pinus propagados in vitro, onde não houve diferença significativa no enraizamento dessa espécie sob diferentes espectros de luz (NIEMI et al., 2005). Em trabalho realizado com ameixeira, Magalhães Junior \& Peters (1991) observaram que intensidade luminosa mais baixa aumentou o número de raízes por broto, no entanto, a percentagem de brotos com raízes secundárias e o comprimento das raízes foram beneficiados pelo aumento da intensidade luminosa na sala de crescimento. Segundo
Tricoli et al. (1985), o estímulo dado ao enraizamento in vitro é resultado da soma do AIA (ácido indol acético) endógeno dos brotos, com possíveis adições de auxinas ao meio. Sendo assim, pode-se supor que os resultados obtidos por meio de uma possível degradação das auxinas pelas altas intensidades luminosas, uma vez que esse fitormônio ou regulador é fotoxidativo (HESS, 1975).

Não houve diferença estatística para número de broto entre os ambientes de cultivo, tanto sala de crescimento como casa-de-vegetação com variação da qualidade espectral. A liberação da dominância apical resulta na formação de brotos axilares, tanto pela fotoxidação de auxinas em altas intensidades luminosas como pela degradação desse regulador pela luz azul (CHEE \& POOL, 1989).

Características anatômicas: As folhas de Dendranthema grandliflorum cv. Rage cultivadas sob diferentes espectros de luz, são hipoestomáticas apresentando estômatos apenas na fase abaxial da folha e seus estômatos do tipo anomocíticos e as células guardas de formato elíptico (Figura 1).

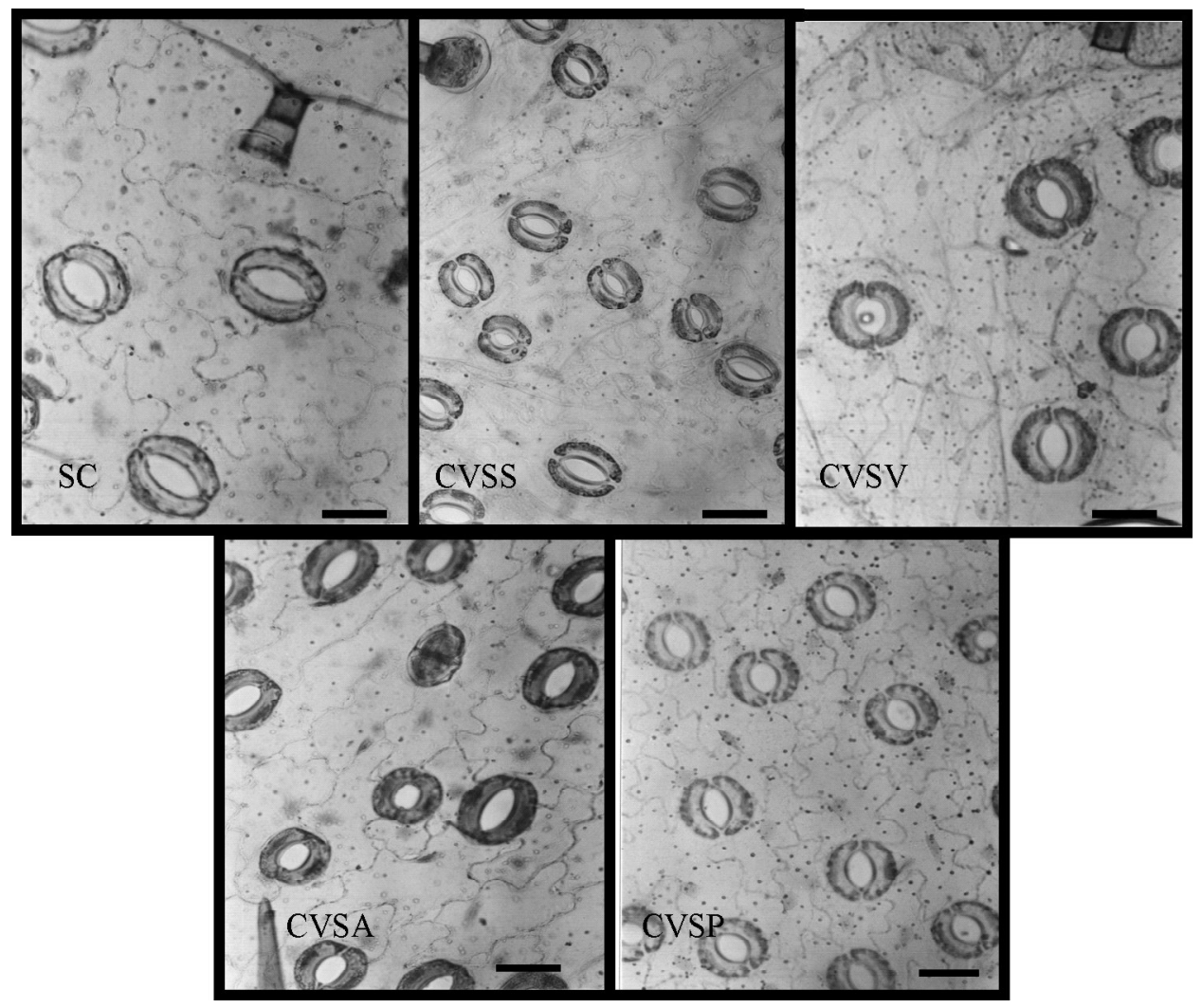

Figura 1 - Secções paradérmicas na superfície abaxial de folhas de crisântemo. $\mathrm{SC}=$ sala de crescimento; CVSS $=$ casade-vegetação sem sombrite; CVSV = casa-de-vegetação sombrite vermelho; CVSA = casa de vegetação sombrite azul e

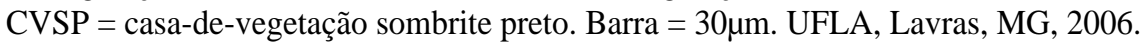


Para densidade de estômatos, houve diferenças significativas entre os tratamentos aplicados, com as maiores densidades de estômatos observadas no cultivo em casa-de-vegetação sem proteção de sombrite, seguido de casa-de-vegetação com sombrite vermelho, os quais não diferiram entre si (Tabela 3). Resultados inferiores foram registrados em sala de crescimento, casa-de-vegetação sombrite azul e preto, corroborando com os resultados obtidos por Dignart (2006) que, trabalhando com Cattleya walkeriana, obteve maiores densidades em casa-de-vegetação sem sombrite. Rajapske \& Kelly (1993), verificaram menor densidade estomática, trabalhando também com crisântemo cultivados sob filtros de $\mathrm{CuSO}_{4}$, que produz os mesmos efeitos de filtros de luz azul.

Quanto aos diâmetros polar e equatorial, foram observados maiores diâmetros em propágulos de crisântemo cultivadas em casa-de-vegetação sem proteção de sombrite, seguido dos tratamentos com malhas coloridas, que não diferiram entre si estatisticamente. Dignart (2006) observou que o tratamento casa-de-vegetação com sombrite vermelho, mostrou os maiores diâmetros polar e equatorial, em estômatos de folhas de Cattleya walkeriana cultivadas in vitro. $\mathrm{O}$ formato elíptico resulta em uma maior relação dos diâmetros polar e equatorial tal características sugere uma maior funcionalidade desses estômatos (KHAN et al., 2002). Segundo Rocha (2005), quanto maior for a relação diâmetro polar/equatorial, mais elipsóide é o formato do estômato, portanto, maior funcionalidade ele deve apresentar.

Tabela 3 - Densidade estomática, diâmetro polar (DP), diâmetro equatorial (DE) dos estômatos para folhas de plântulas cultivadas de crisântemo sob diferentes ambientes de luz com telas coloridas. $\mathrm{CV}=$ casa-devegetação sob diferentes qualidades de luz.

\begin{tabular}{lccc}
\hline \multicolumn{1}{c}{ Luz } & $\begin{array}{c}\text { Densidade } \\
\left(\mathrm{mm}^{2}\right)\end{array}$ & $\mathrm{DP}(\mu \mathrm{m})$ & $\mathrm{DE}(\mu \mathrm{m})$ \\
\hline $\begin{array}{l}\text { Casa-de- } \\
\text { vegetação }\end{array}$ & $232,4 \mathrm{a}$ & $58,6 \mathrm{a}$ & $43 \mathrm{a}$ \\
CV azul & $101,4 \mathrm{~b}$ & $52,9 \mathrm{~b}$ & $41,5 \mathrm{~b}$ \\
CV preto & $93.3 \mathrm{~b}$ & $53,6 \mathrm{~b}$ & $40,1 \mathrm{~b}$ \\
CV Vermelho & $165,1 \mathrm{a}$ & $54,3 \mathrm{~b}$ & $40,5 \mathrm{~b}$ \\
$\begin{array}{l}\text { Sala de } \\
\text { crescimento }\end{array}$ & $87,2 \mathrm{~b}$ & $42,8 \mathrm{c}$ & $28,7 \mathrm{c}$ \\
\hline
\end{tabular}

*Médias seguidas pela mesma letra não diferem entre si, pelo teste de Scott-Knott, $\mathrm{p}<0,05$.

\section{CONCLUSÕES}

O ambiente de cultivo não promove alterações anatômicas significativas em plantas de Dendranthema grandiflorum cv. Rage cultivadas in vitro.

Recomenda-se o cultivo in vitro de crisântemo em casa-de-vegetação no intuito de reduzir os custos de produção de mudas.

\section{REFERÊNCIAS BIBLIOGRÁFICAS}

ALMEIDA, M. L.; MUNDSTOCK, C. M. O afilhamento da aveia afetado pela qualidade de luz em plantas sob competição. Ciência Rural, Santa Maria, v. 31, n. 3, p. 393-400, maio/jun. 2001.

ANTONOPOLOU, C.; DIMASSI, F.; THERIOS, I.; CHATZISSAVVIDIS, $\mathrm{C}$. The influence of radiation quality on the in vitro rooting and nutrient concentrations of peach rootstock. Biologia Plantarum, Copenhagen, v. 48, n. 4, p. 549-553, 2004.

APPELGREN, M. Effects of light quality on stem elongation of Pelargonium in vitro. Scientia

Horticulturae, Amsterdam, v. 45, n. 3/4, p. 345-351, Jan. 1991.

ARAÚJO, A. G. Micropropagação de Cattleya loddigesii 'tipo': fontes de nitrogênio, qualidade de luz, sacarose e ácido giberélico. 2007. 74 p. Tese (Doutorado em Agronomia/Fitotecnia) - Universidade Federal de Lavras, Lavras, 2007.

CHEE, R.; POOL, R. M. Morphogenetic responses to propate trimming, spectral irradiance, and photoperiod of grapevine shoots recultured in vitro. Journal of the American Society for Horticultural Science,

Alexandria, v. 114, n. 2, p. 350-354, Mar. 1989.

DIGNART, S. L. Luz e sacarose na micropropagação de Cattleya walkeriana: alterações anatômicas e

fisiológicas. 2006. 132 p. Dissertação (Mestrado em Agronomia/Fisiologia Vegetal) - Universidade Federal de Lavras, Lavras, 2006.

DOUSSEAU, S.; ALVARENGA, A. A. DE.; CASTRO, E. M. DE.; SOARES, R. P.; EMRICH, E. B.; MELO, L. A. DE. Anatomia foliar de Tabebuia serratifolia (Vahl) Nich. (Bignoniaceae) propagadas in vitro, in vivo e durante a aclimatização. Ciência e Agrotecnologia, Lavras, v.32, n.6, p.1694-1700, nov./dez. 2008. 
ESKINS, K.; BEREMAND, P. D. Light-quality irradiancelevel control of lightharvesting complex of photosystem 2 in maize mesophyll cells: evidence for a low fluence rate threshold in blue-light reduction of mRNA and protein. Physiologia Plantarum, Copenhagen, v. 78, n. 3, p. 435-440, Mar. 1990.

HESS, D. Plant physiology: molecular, biochemical, and physiological fundamentals of metabolism and development. New York: Springer-Verlag, 1975. 333 p.

HUNTER, D. C.; BURRIT, D. J. Light quality influences adventitious shoot production from cotyledon explants of lettuce (Lactuca sativa). In Vitro Cell, Development Biology of Plants, New York, v. 40, n. 2, p. 215-220, Mar./Apr. 2001.

KHAN, P. S. S. V. et al. Growth and net photosynthetic rates of Eucalyptus tereticornis Smith under photomixotrophic and various photoautotrophic micropropagation conditions. Plant Cell, Tissue and Organ Culture, Amsterdam, v. 71, p. 141-146, 2002.

LABORIAU, L. G.; OLIVEIRA, J. G.; SALGADOLABORIAU, M. I. Transpiração de Schizolobium parahyba (vell) Toledo I: comportamento na estação chuvosa, nas condições de caeté, Minas Gerais. Anais da Academia Brasileira de Ciências, Rio de Janeiro, v. 33, n. 2, p. 237-252, 1961.

LEE, D. W. Effects of irradiance and spectral quality on leaf structure and function in seedlings of two southeast asian Hopea (Dipeterocarpaceae) species. American Journal of Botany, Columbus, v. 87, n. 4, p. 447-455, Apr. 2000.

MAGALHÃES JUNIOR, A. M. M.; PETERS, J. A. Cultura "in vitro" de ameixeira: efeito do ácido indolbutírico, tipo de lâmpada e intensidade luminosa no enraizamento. Revista Brasileira de Fisiologia Vegetal, Campinas, v. 3, n. 1, p. 57-61, 1991.

MARKS, T. R.; SIMPSON, S. E. Effect of irradiance on shoot development in vitro. Plant Growth Regulation, Dordrecht, v. 28, n. 2, p. 133-142, June 1999.

MURASHIGE, T.; SKOOG, F. A revised médium for rapid growth and bioassays with tobacco tissue cultures.

Physiologia Plantrarum, Copenhagen, v. 15, n. 3, p. 473497, Mar. 1962.
NIEMI, K. et al. Light sources with different spectra affect root and mycorrhiza formation in Scot pine in vitro. Tree Physiology, Victoria, v. 25, n. 1, p. 123-128, Jan. 2005.

RADMANN, E. B.; BRAGA, E. J. B.; KARAN, M. A. L.; POSADA, M. A. C.; PETERS, J. A. Influência da densidade de fluxo luminoso na qualidade de plantas micropropagadas de Gypsophila paniculata L. Revista Brasileira de Agrociência, Pelotas, v. 7, n. 3, p. 171-175, 2001.

RAJAPSKE, N. C.; KELLY, J. W. Spectral filters influence transpirational water loss in Chrysanthemum.

HortScience, Alexandria, v. 28, n. 10, p. 999-1001, Oct. 1993.

REZENDE, R. K. S.; PAIVA, L. V.; PAIVA, R.; CHALFUN JÚNIOR, A.; TORGA, P. P.; CASTRO, E. M. DE. Organogênese em capítulos florais e avaliação de características anatômicas da folha de Gerbera jamesonni Adlam. Ciência e Agrotecnologia, Lavras, v.32, n. 3, p. 821-827, maio/jun. 2008.

ROCHA, H. S. Luz e sacarose na micropropagação da bananeira 'prata anã': alterações morfoanatômicas. 2005. 98 p. Dissertação (Mestrado em Agronomia/Fitotecnia) Universidade Federal de Lavras, Lavras, 2005.

SAEBO, A.; KREKLING, T.; APPELGREN, M. Light quality affects photosynthesis and leaf anatomy of birch plantlets in vitro. Plan Cell, Tissue and Organ Culture, Amsterdam, v. 41, n. 2, p. 177-185, May 1995.

SAITOU, T.; HASHIDUME, A.; TOKUTOMI, S.; KAMADA, H. Reduction of phytochrome level and light-induced formation of adventitious shoots by introduction of antisense genes for phytochrome A in horseradish hairy roots. Plant Cell, Tissue and Organ Culture, Amsterdam, v. 76, p. 45-51, 2004.

SCHUERGER, A. C.; BROWN, C.; STRYJEWSKI, E. C. Anatomical features of pepper plants (Capsicum annиит L.) growth under red light emitting diodes supplemented with blue or far-red light. Annals of Botany, London, v. 79, n. 3, p. 273-282, Mar. 1997.

SILVA, M. H.; DEBERGH, P. C. The effect of light quality on the morphogenesis of in vitro cultures of Azorina vidalii (Wats.) Feer. Plant Cell, Tissue and Organ Culture, Amsterdam, v. 51, n. 3, p. 187-193, 1997. 
SIMS, D. A.; PEARCY, R. W. Response of leaf anatomy and photosynthetic capacity in Alocasia macrorrhiza (Araceae) to a transfer from low to hight light. American Journal of Botany, Columbus, v. 79, n. 4, p. 449-455, Apr. 1992.

TAIZ, L.; ZEIGER, E. Fisiologia vegetal. 3. ed. Porto Alegre: Artmed, 2004. 841 p.

TRICOLI, W. D.; MAYMNARD, C. A.; DREW, A. P. Tissue culture of propagation of matures trees of
Prunus serotina Enrh. I. establishment, multiplication, and rooting "in vitro". ForestSic., v. 31, n. 1, p. 201-208, 1985.

TSEGAY, B. A.; OLSEN, J. E.; JUNTILLA, O. Effect of red and far-red light on inhibition of hypocotyls elongation in ecotypes of Betula pendula Roth. American Journal of Biotechnology, v. 4, n. 1, 2005. Disponível em: <http:// iwww.academicjournals.org/ĀJB'. Acesso em: 24 set. 2005 